\title{
Erratum to: Single nucleotide polymorphism analysis of Korean native chickens using next generation sequencing data
}

\author{
Dong-Won Seo $\cdot$ Jae-Don Oh $\cdot$ Shil Jin $\cdot$ Ki-Duk Song $\cdot$ Hee-Bok Park $\cdot$ \\ Kang-Nyeong Heo $\cdot$ Younhee Shin · Myunghee Jung · Junhyung Park • \\ Cheorun Jo $\cdot$ Hak-Kyo Lee $\cdot$ Jun-Heon Lee
}

Published online: 15 January 2015

(C) Springer Science+Business Media Dordrecht 2015

\section{Erratum to: Mol Biol Rep \\ DOI 10.1007/s11033-014-3790-5}

Acknowledgements were omitted in the original publication and should be read as "This work was supported by a grant from the Next-Generation BioGreen 21 Program (No. PJ0081330), Rural Development Administration, Republic of Korea."

The online version of the original article can be found under doi:10.1007/s11033-014-3790-5.

D.-W. Seo $\cdot$ S. Jin $\cdot$ J.-H. Lee $(\varangle)$

Department of Animal Science and Biotechnology, Chungnam

National University, Daejeon 305-764, Korea

e-mail: junheon@cnu.ac.kr

J.-D. Oh · K.-D. Song $\cdot$ H.-K. Lee $(\bowtie)$

Genomic Informatics Center, Hankyong National University, Ansung 456-749, Korea

e-mail: breedlee@empal.com

H.-B. Park

Institute of Agriculture and Life Science, Gyeongsang National University, Jinju 660-701, Korea

K.-N. Heo

Poultry Science Division, National Institute of Animal Science, RDA, Cheonan 331-801, Korea

Y. Shin $\cdot$ M. Jung $\cdot$ J. Park

Codes Division, Insilicogen, Suwon 441-813, Korea

C. Jo

Department of Agricultural Biotechnology, Center for Food and Bioconvergence, and Research Institute for Agriculture and Life Science, Seoul National University, Seoul 151-921, Korea 